\title{
Article \\ Effect of Mold Electromagnetic Stirring on the Flow and Solidification of $\Phi 800$ mm Round Blooms
}

\author{
Tao Wang ${ }^{1}$, Lianwang Zhang ${ }^{2, *}$, Hongjian Wu ${ }^{1}$, Xiaobing Zhang ${ }^{1}$, Yukai Jin ${ }^{1}$, Peiqi Yang ${ }^{1}$ and $\mathrm{Changjun} \mathrm{Xu}^{1, *}$ \\ 1 School of Material and Metallurgy, University of Science and Technology Liaoning, Anshan 114051, China; \\ w15642237857@163.com (T.W.); keene1998@163.com (H.W.); zxb244512@163.com (X.Z.); \\ jin15566285877@163.com (Y.J.); 18191508128@163.com (P.Y.) \\ 2 Yingkou Institute of Technology, Yingkou 115100, China \\ * Correspondence: jassonas@163.com (C.X.); Tel.: +86-041-2592-9554 (C.X.); zhanglianwang92@163.com (L.Z.)
}

check for updates

Citation: Wang, T.; Zhang, L.; Wu, H. Zhang, X.; Jin, Y.; Yang, P.; Xu, C. Effect of Mold Electromagnetic Stirring on the Flow and Solidification of $\Phi 800 \mathrm{~mm}$ Round Blooms. Processes 2022, 10, 430 . https://doi.org/10.3390/pr10020430

Academic Editor: Peng Lan

Received: 26 January 2022

Accepted: 17 February 2022

Published: 21 February 2022

Publisher's Note: MDPI stays neutral with regard to jurisdictional claims in published maps and institutional affiliations.

Copyright: (C) 2022 by the authors. Licensee MDPI, Basel, Switzerland. This article is an open access article distributed under the terms and conditions of the Creative Commons Attribution (CC BY) license (https:// creativecommons.org/licenses/by/ $4.0 /)$

\begin{abstract}
Knowing the effect of electromagnetic force on fluid flow and solidification within the molds of large-size round blooms is of paramount importance to minimize internal and external defects. In this regard, a three-dimensional coupling model is established, containing magnetohydrodynamics, fluid flow, and heat transfer within the mold, and a new approach for the uniformity of the initial shell is presented. Meanwhile, the effect of stirring parameters on fluid flow and solidification is discussed. The results show that M-EMS can significantly change the temperature and velocity distribution within the mold. These changes can stabilize the level fluctuations and make the initial shell uniform. The maximum industrial height fluctuation was reduced from $1.9 \mathrm{~mm}$ to $1.3 \mathrm{~mm}$ when the stirring intensity was $375 \mathrm{~A} / 3 \mathrm{~Hz}$. The stirring intensity of M-EMS is relatively ideal.
\end{abstract}

Keywords: numerical simulation; mold electromagnetic stirring; flow and solidification; round bloom; vertical continuous casting

\section{Introduction}

In recent years, vertical-bending and arc casters are widely employed in alloy steel continuous casting due to their high production efficiency. With the ever-growing dimensions of products, such as bearings and pipelines, large-size special steels are mainly produced by ingot casting and electroslag remelting. Recently, vertical continuous casting [1] and vertical semi-continuous casting [2] have been applied as a combination of ingot casting and conventional continuous casting to produce large-size round blooms to enhance large-size special steel production efficiency. Generally, the application of the modern technological packages used today in vertical-bending and arc continuous casting can also be used in vertical continuous casting, such as mold electromagnetic stirring (M-EMS). The best-known metallurgical results of M-EMS are non-contact force, cleanliness, and easy installation.

The key equipment of continuous casting is the mold, which controls the initial solidification, floating of inclusions, and melting of flux powder. The strand quality is related to the molten steel flow conditions, and it is necessary to control the molten steel flow within the mold because the characteristics of large-size round blooms are slow casting speed, adverse solidification conditions, and unchanged flow form if there is no net external force. As a non-contact force, electromagnetic force is a good way to affect the molten steel flow within the mold. There have been many studies focused on the flow process of the molten steel with electromagnetic stirring. Some researchers did not consider heat transfer but considered fluid flow [3-5]; some researchers thought the comprehensive consideration of heat transfer and fluid flow to have more practical value [6-11]; and several researchers have studied macrosegregation in the billet with M-EMS [12-15]. However, it is unknown whether the solidification and flow characteristics under electromagnetic stirring summarized by predecessors can be applied to large-size round blooms. Liu et al. [16] reported some information about $\Phi 600 \mathrm{~mm}$ round blooms. Compared with the continuous 
casting process parameters used in their study, the process parameters in the present work are different, especially the casting speed, the type and parameters of the electromagnetic stirring, and the diameter of the billet. In the case of the slow casting speed, the final steel quality will be affected by any change in the process parameters. Zhang et al. [17] reported mold metallurgical behavior under electromagnetic stirring, and the diameter of the round bloom used in their study was $\Phi 800 \mathrm{~mm}$; however, only the direct phenomena are researched, which are not sufficient and are difficult to measure. Uniform initial shell growth and liquid level can be a good complement.

In the present study, the installation position of M-EMS was fixed in industrial production, and thus the stirring parameter was of paramount importance to alloy steel production. The purpose of the present study was to investigate the effect of M-EMS parameters on the magnetic flow-temperature fields of a large-size round bloom. The suitableness of M-EMS could simply be characterized by knowing and comparing the thickness inhomogeneity of the initial shell and the height fluctuation of the liquid level; meanwhile, the electromagnetic stirring technology of the round bloom was optimized.

\section{Simulation Model}

In the present study, a three-dimensional mathematical model of the round bloom solidification process was established by the finite volume method. The mathematical description was divided into four parts: magnetic field, fluid flow, heat transfer and solidification, and multiphase flow model. Details about the model of the magnetic field of the present study have been presented elsewhere [18].

\subsection{Assumptions}

Unfortunately, measuring and analyzing molten steel flow at high temperatures within the mold, under the influence of the M-EMS with different operation parameters, is still difficult, if not out of the question. Accordingly, the model was established by the following assumptions in order to simplify the simulation process.

1. The effect of the internal reaction in molten steel was ignored, and the external temperature was constant.

2. The molten steel was considered to be an incompressible, Newtonian fluid.

3. The influence of the solidification shrinkage, mold oscillation, and taper have not been considered in this study.

4. The influence of the fluid flow on the magnetic field was neglected.

5. The mushy zone was recognized as a porous medium and described by Dacy's law.

6. The heat transfer caused by the induced current was ignored due to the Joule heat produced by the induced current being very small.

\subsection{Fluid Flow}

The fluid flow during the continuous casting process can be described by the following equations:

$$
\begin{gathered}
\frac{\partial\left(\rho u_{j}\right)}{\partial x_{j}}=0 \\
\rho \frac{\partial u_{i} u_{j}}{\partial x_{j}}=-\frac{\partial P}{\partial x_{j}}+\frac{\partial}{\partial x_{j}}\left[\mu_{e f f}\left(\frac{\partial u_{i}}{\partial x_{j}}+\frac{\partial u_{j}}{\partial x_{i}}\right)\right]+\rho g_{i}+F_{E}+S_{p},
\end{gathered}
$$

where $\rho$ is the density, $u_{j}$ is the velocity of the direction in $x_{j}$, and $P$ is the static pressure. $\mu_{\text {eff }}$ is the effective viscosity, which is the sum of the laminar viscosity $\mu_{l}$ and turbulent viscosity $\mu_{t} . g_{i}$ is the acceleration of gravity. $F_{E}$ is the electromagnetic force source term, and $S_{p}$ is the sink term. 
The sink term $S_{P}$ in Equation (2), which is used to reasonably describe the movement of molten steel in the mushy zone, can be given by

$$
S_{P}=\frac{(1-\beta)^{2}}{\left(\beta^{3}+\lambda\right)} A_{\mathrm{mush}}\left(V-V_{P}\right)
$$

where $\beta$ is the volume fraction of liquid phase, $\lambda$ is a very small positive number which can be taken as $0.0001, A_{\text {mush }}$ is the mushy zone coefficient, $V$ is the velocity, and $V_{P}$ is the velocity of solid.

The RNG (Renormalization group) $k-\varepsilon$ turbulent model can be used to describe the low-Reynolds-number turbulence of fluid flow in this study. The equation can be written as follows:

$$
\begin{gathered}
\frac{\partial}{\partial t}(\rho k)+\frac{\partial}{\partial x i}\left(\rho k u_{i}\right)=\frac{\partial}{\partial x_{j}}\left(\alpha_{k} \mu_{e f f} \frac{\partial k}{\partial x_{j}}\right)+G_{k}+G_{b}-\rho \varepsilon+S_{k \prime} \\
\frac{\partial}{\partial t}(\rho \varepsilon)+\frac{\partial}{\partial x_{i}}\left(\rho \varepsilon u_{i}\right)=\frac{\partial}{\partial x_{j}}\left(\alpha_{\varepsilon} \mu_{e f f} \frac{\partial \varepsilon}{\partial x_{j}}\right)+C_{1 \varepsilon} \frac{\varepsilon}{k}\left(G_{k}+C_{3 \varepsilon} G_{b}\right)-C_{2 \varepsilon} \rho \frac{\varepsilon^{2}}{k}-R_{\varepsilon}+S_{\varepsilon},
\end{gathered}
$$

where $G_{k}$ is the turbulent kinetic energy generated by the average velocity gradient, $G_{b}$ is the turbulent kinetic energy generated by buoyancy, and $S_{k}$ and $S_{\varepsilon}$ are the source terms. The turbulent model constants are listed in Table 1.

Table 1. Turbulent model constant.

\begin{tabular}{ll}
\hline$C_{1 \varepsilon}$ & $C_{2 \varepsilon}$ \\
\hline 1.42 & 1.68 \\
\hline
\end{tabular}

\subsection{Heat Transfer and Solidification}

For the heat transfer and solidification process of the round bloom, the energy equation can be described by

$$
\frac{\partial}{\partial t}(\rho H)+\nabla \cdot(\rho V H)=\nabla \cdot(k \nabla T)+S,
$$

where $k$ is the thermal conductivity, $T$ is the temperature, $S$ is the source term, and $H$ is the enthalpy, which can be described as

$$
H=h_{r e f}+\int_{T_{r e f}}^{T} C_{p} d T+\beta \Delta H
$$

where $h_{r e f}$ is the reference enthalpy, $C_{P}$ is the specific heat, $\Delta H$ is the latent heat, and $\beta$ is the liquid fraction, which can be expressed as

$$
\beta=\left\{\begin{array}{lc}
0 & T \leq T_{S} \\
\frac{T-T_{s}}{T_{l}-T_{s}} & T_{s}<T<T_{l} \\
1 & T_{l} \leq T
\end{array}\right.
$$

where $T_{l}$ and $T_{S}$ are the liquidus temperature and solidus temperature, respectively.

\subsection{Multiphase Flow Model}

In order to describe the height fluctuation of liquid level, the continuity equation can be written as

$$
\frac{1}{\rho_{q}}\left[\frac{\partial}{\partial t}\left(a_{q} \rho_{q}\right)+\frac{\partial}{\partial x_{i}}\left(a_{q} \rho_{q} u_{i}\right)\right]=S_{a q},
$$


where $\rho_{q}$ is the density of phase " $q$ " and $a_{q}$ is the volume fraction of phase " $q$ " in the computational element, which can be described as follows:

$$
\sum_{q=1}^{n} a_{q}=1
$$

where if $a_{q}=0$, there is no phase " $q$ " in the computational element; if $0<a_{q}<1$, there is a phase " $q$ " and other phases in the computational element; and if $a_{q}=1$, there is only phase " $q$ " in the computational element.

\section{Boundary Conditions}

The schematic diagram of the mold electromagnetic stirring model is shown in Figure 1, and the meshing and submerged entry nozzle (SEN) are shown in Figure 2. The calculation domain was extended to the end of the secondary cooling zone in order to fully understand the behavior of molten steel within the mold. In the present study, the grid consists of 720,880 cells and 750,496 nodes, which are generated by the ICEM through the structured grid approach. The solute element content and relevant technical parameters of the round bloom are listed in Tables 2 and 3, respectively. The boundary conditions implemented in fluid flow and heat transfer are described as follows.

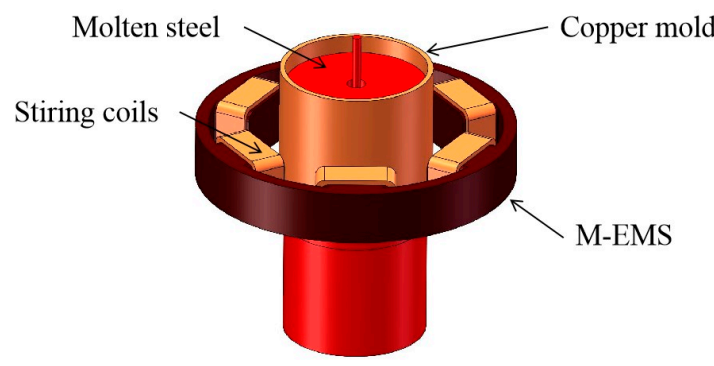

Figure 1. Schematic diagram of mold electromagnetic stirring.
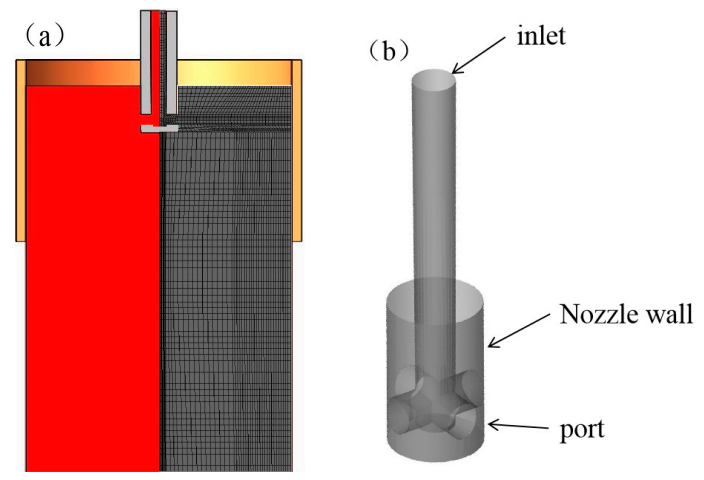

Figure 2. Schematic diagram of meshing and four-port nozzle. (a) Meshing; (b) SEN.

Table 2. Steel solute element content.

\begin{tabular}{ccccccccc}
\hline Elements & C & Si & Mn & Cr & Mo & Ni & P & S \\
\hline Content, wt $(\%)$ & 0.08 & 0.25 & 0.44 & 8.83 & 0.4 & 0.27 & 0.013 & 0.004 \\
\hline
\end{tabular}


Table 3. Technical parameters of round bloom caster.

\begin{tabular}{cc}
\hline Items & Value \\
\hline Effective height of mold, $\mathrm{mm}$ & 600 \\
Length of secondary cooling zone, $\mathrm{mm} / \mathrm{mm} / \mathrm{mm}$ & $240 / 800 / 800$ \\
Inner diameter of $S E N$ inlet, $\mathrm{mm}$ & 45 \\
Inner diameter of $S E N$ port, $\mathrm{mm} \times \mathrm{mm}$ & $40 \times 45$ \\
Outer diameter of $S E N, \mathrm{~mm}$ & 55 \\
Sectional dimension, $\mathrm{mm}$ & 800 \\
Distance from stirrer center to meniscus, mm & 350 \\
SEN submergence depth, mm & 180 \\
Casting speed, $\mathrm{m} / \mathrm{min}$ & 0.16 \\
\hline
\end{tabular}

\subsection{Meniscus}

In view of the thermal insulation effect of the mold, the upper surface of the model was set to an adiabatic surface, and the normal gradient of other variables was zero.

\subsection{Inlet}

The casting speed was used as the standard criterion for defining the inlet velocity. The calculation method of the inlet velocity is as follows:

$$
V_{\text {in }}=\frac{V_{p} S_{\text {cast }}}{S_{S E N}},
$$

where $V_{\text {in }}$ is the inlet velocity, $S_{\text {cast }}$ and $S_{\text {SEN }}$ are the casting and SEN cross-section area, respectively. Inlet temperature equaled to casting temperature. Additionally, the initial turbulence energy and dissipation rate can be computed using the following semiempirical formula:

$$
\begin{gathered}
k=1.5\left(i V_{i n}\right)^{2}, \\
\varepsilon=\frac{0.09^{0.75} k^{1.5}}{0.07 l},
\end{gathered}
$$

where $l$ is the inner diameter of $S E N$, and $i$ is the turbulence intensity, which can be written as

$$
i=0.16\left(R_{e}\right)^{-0.125},
$$

where $R_{e}$ is the Reynolds number.

\subsection{Strand Surface}

According to the principle of thermal equilibrium, different types of heat transfer conditions and zero-diffusion flux boundary conditions were applied. Boundary conditions are given as follows.

Mold zone:

Assuming that the heat exchange rate between the mold and the cooling water is $100 \%$, there is no thermal loss, and the heat flux of the mold can be written as

$$
\bar{q}=\frac{Q_{W} C_{W} \Delta T_{W}}{A},
$$

where $Q_{W}$ is the water flow rate of the mold, $C_{W}$ is the specific heat of water, $\Delta T_{W}$ is the temperature difference of the water between the copper tube inlet and outlet, and $A$ is the contact region between the molten steel and the mold.

Secondary cooling zone:

$$
h=708 \cdot w^{0.75} \cdot T_{W}{ }^{-1.2}+0.136,
$$

where $w$ is the water flow rate and $T_{W}$ is the strand surface temperature. 


\subsection{Outlet}

The "outflow" boundary condition was adopted for the model outlet in order to observe the law of mass conservation and fully developed fluid flow.

\subsection{Thermophysical Parameters}

In this study, the operating conditions of the M-EMS and the liquid steel are shown in Table 4, and the thermophysical parameters of the liquid steel are shown in Table 5.

Table 4. Operation conditions.

\begin{tabular}{cc}
\hline Items & Value \\
\hline Superheat, $\mathrm{K}$ & 30 \\
M-EMS current density, A & $200-600$ \\
M-EMS current frequency, Hz & $1-5$ \\
Electrical conductivity, S/m & $7.16 \times 10^{5}$ \\
Magnetic permeability, $\mathrm{H} / \mathrm{m}$ & $1.257 \times 10^{-6}$ \\
\hline
\end{tabular}

Table 5. Thermophysical parameters of liquid steel.

\begin{tabular}{cc}
\hline Items & Value \\
\hline Density, $\mathrm{kg} / \mathrm{m}^{3}$ & 7200 \\
Viscosity, pa s & 0.0053 \\
Specific heat, J/kg k & 822 \\
Thermal conductivity, W/m k & 52.535 \\
Latent heat, $\mathrm{J} / \mathrm{kg}$ & 268,000 \\
Liquidus temperature, $\mathrm{K}$ & 1817 \\
Solidus temperature, $\mathrm{K}$ & 1739 \\
Mushy zone parameters, $\mathrm{kg} / \mathrm{m}^{3} \mathrm{~s}$ & $1 \times 10^{8}$ \\
\hline
\end{tabular}

\section{Solution Procedure}

The numerical solution was split into two parts. Firstly, the finite element software (Ansys Maxwell) was applied to calculate the electromagnetic force in the round bloom; secondly, the finite volume software (Ansys Fluent) was applied to calculate the coupling field, and the electromagnetic force was added to the flow field as a momentum source term by user-defined functions (UDF), which was used to simulate the coupling of fluid flow, heat transfer, and solidification.

In the present study, the method of the under-relaxation factor was adopted to make each equation converge. The under-relaxation factor in the present study is 0.2 . Meanwhile, the convergence residual was set to $1 \times 10^{-5}$. It is obvious that when the residual of each variable was reduced below the convergence residual and each variable of the calculated result did not essentially change, the calculation could be regarded as convergence. The default Least Squares Cell-Based was used to calculate the gradient. The second-order upwind scheme was used for the convective term of the flow equation and all scalar equations, except the turbulence, and the first-order upwind scheme was used for the turbulent physical quantity correlation equation.

\section{Results and Discussion}

To verify the electromagnetic model used in the present study, a model 3600 digital, high-precision, three-dimensional Gaussian meter (CH-HALL, Beijing, China) with a lowfrequency alternating magnetic field acquisition module was used to measure the magnetic field inside of the mold. The positions where the measuring points are located are shown in Figure 3. 


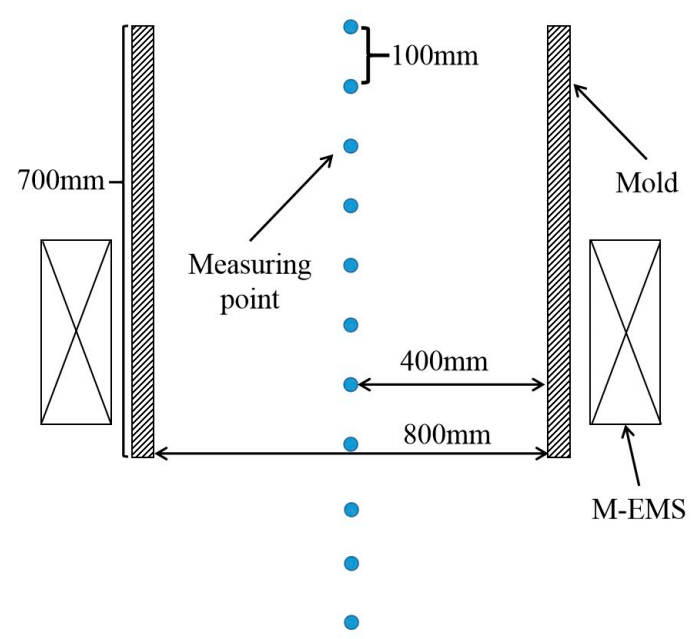

Figure 3. Schematic diagram of the measuring points.

The magnetic flux density predicted by the present model was compared to the measurement results, as shown in Figure 4. According to this figure, the simulated results are in agreement with the measured results. More remarkable is the difference between the simulated results and the measured results; this is owing to the assumptions and simplifications in the modeling of the electromagnetic field. The operating environment must not overlook the effects on practical conditions or the measurement errors. The validated electromagnetic model was further used to calculate magnetic flux density distribution.

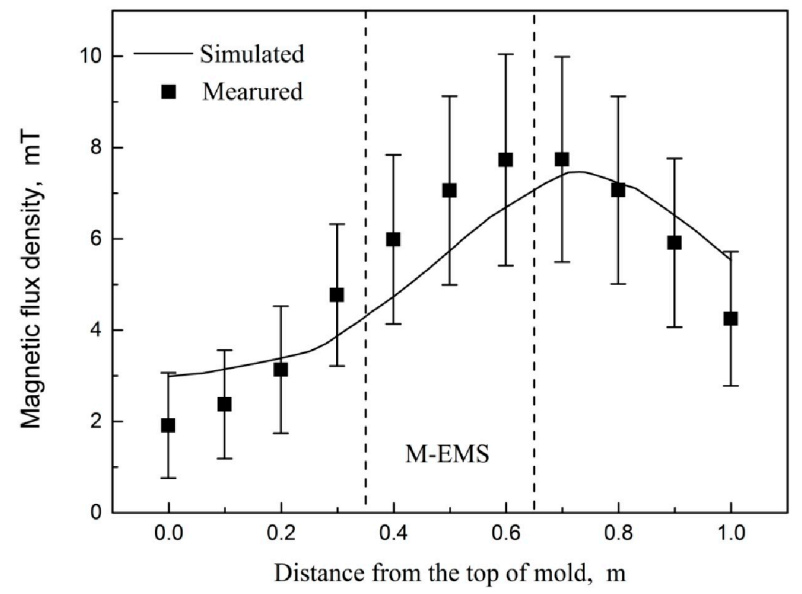

Figure 4. Comparison of simulated and measured results.

The initial solidification of the steel shell in the continuous casting mold is of paramount importance because it creates the surface of the final product. In the present study, a new approach for initial shell growth discrimination can be described as follows: eight measuring lines were selected on the lateral section of the mold outlet, and one point was selected at which the solid fraction on the measuring line reached 0.7 [19]; at the same time, the point was the closest to the center of the cross-section, and thus the present point position was the front of the initial shell on the measuring line. Similarly, sixteen points were selected, and the minimum value was subtracted from the maximum value. The difference value can be interpreted as the uniformity of the initial shell. If the shell is at its most uniform, the difference value is zero. The discrimination method is shown in Figure 5. 


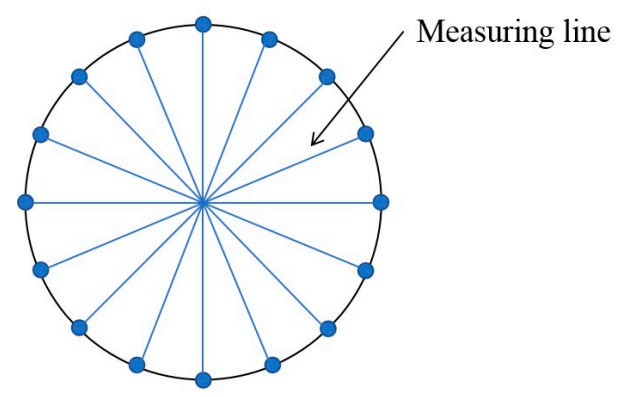

Figure 5. Schematic diagram of the discrimination method used in this study.

\subsection{Magnetic Flux Density at the Different Stirring Intensities}

Towards a clearer understanding of the positions where the measuring lines are located, Figure 6 shows the axial and radial measuring lines of the longitudinal section. Figure 7 shows the magnetic flux density distribution of the axial and radial measuring lines, Figure 7a,c at the same current frequency and different current intensity and Figure $7 \mathrm{~b}, \mathrm{~d}$ at the same current intensity and different current frequency. The magnetic flux densities are greater near the stirrer position compared to the other positions of the billet, as shown in Figure 7a,b. Meanwhile, the maximum magnetic flux density concentrates on the outlet position of the mold, which can be explained by the effect of the copper tube on magnetic shielding. Because the permeability of the copper tube is greater than that of the billet, it is thus easier for the magnetic induction lines to accumulate in the copper tube. Additionally, the magnetic flux densities are greater near the edge compared to the center of the mold outlet, as shown in Figure 7c,d. This is referred to as the "surface effect" from the alternating electromagnetic field. The "surface effect" not only exists in general physical research but also in the continuous casting process. Moreover, as the current intensity and current frequency increase, the magnetic flux density increases and decreases, respectively. Additionally, with every $100 \mathrm{~A}$ increase in current intensity, the axial and radial magnetic flux density increases by $1.6 \mathrm{mT}$ and $2.4 \mathrm{mT}$, respectively.

With the same current frequency and different current intensity used in M-EMS, only the maximum magnetic flux density is changed without changing its position in the billet, as shown in Figure 7a. Meanwhile, the distribution patterns are essentially the same, and there is a linear relationship between the current intensity and maximum magnetic flux density, as shown in Figure 7c.

It should be noted that the position where the maximum magnetic flux density is located is different, as shown in Figure $7 \mathrm{~b}$, because there is an inverse relationship between the surface effect depth and current frequency, electrical conductivity, and magnetic permeability; however, the electrical conductivity and magnetic permeability are essentially constant in the present study, and thus the surface effect depth is mainly determined by the current frequency. The lower the current frequency, the deeper the surface effect depth, and the less obvious the surface effect. The maximum magnetic flux density is essentially the same, and the distribution form is different, as shown in Figure $7 \mathrm{~d}$. Thus, briefly, the magnitude of magnetic flux density is mainly determined by current intensity, and the distribution form of magnetic flux density is mainly determined by current frequency. 


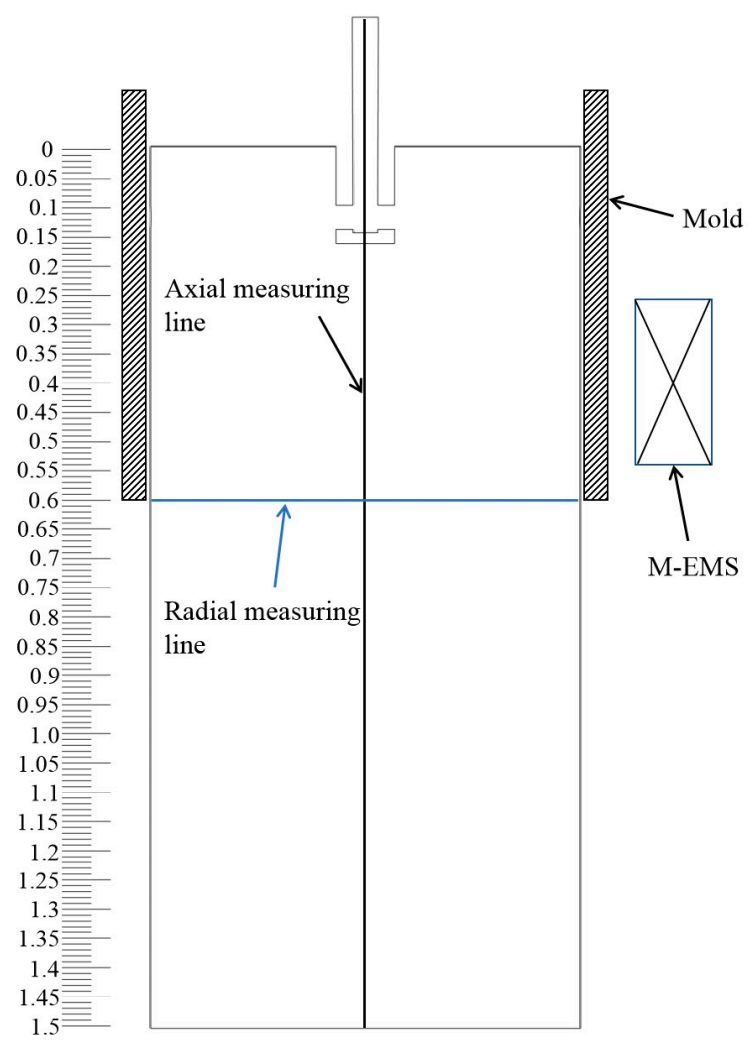

Figure 6. Schematic diagram of the axial and radial measuring lines.
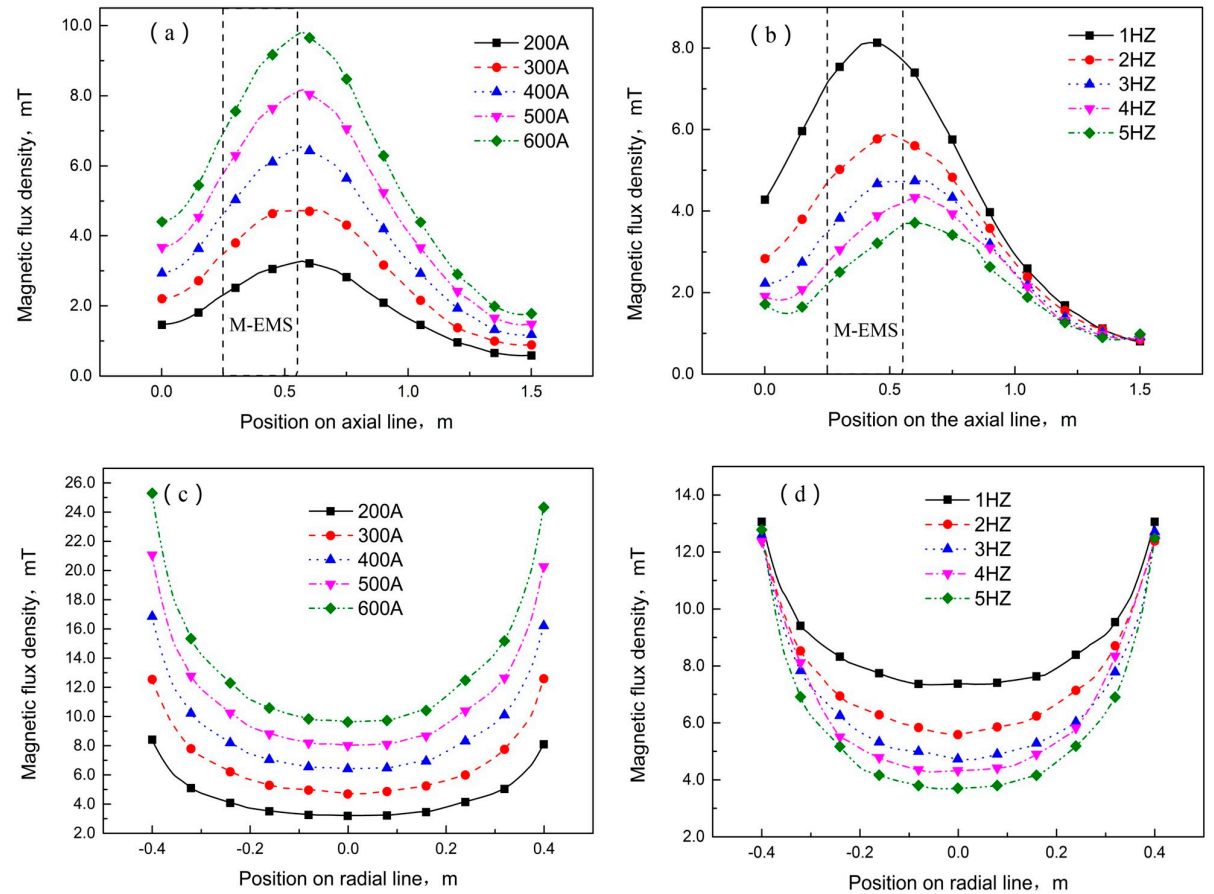

Figure 7. Magnetic flux density: $(\mathbf{a}, \mathbf{b})$ on the axial measuring line; $(\mathbf{c}, \mathbf{d})$ on the radial measuring line.

\subsection{Effect of the Application of M-EMS on Behavior of Flow and Solidification}

Figure 8 demonstrates the velocity distribution on the longitudinal section, both without M-EMS and with M-EMS. The M-EMS parameter is determined to be $400 \mathrm{~A} / 3 \mathrm{~Hz}$. Whether inside or outside of the lateral section where the stirrer is located, molten steel affected by M-EMS is conducive to inclusions floating. According to Figure 8b, there are 
some significant differences in velocity between the left and right in the range of $Z=0.3 \mathrm{~m}$ to $Z=0.9 \mathrm{~m}$. This implies that molten steel flow, driven by electromagnetic force, is asymmetrical. The electromagnetic force promotes the molten steel in one direction and inhibits it in the other.

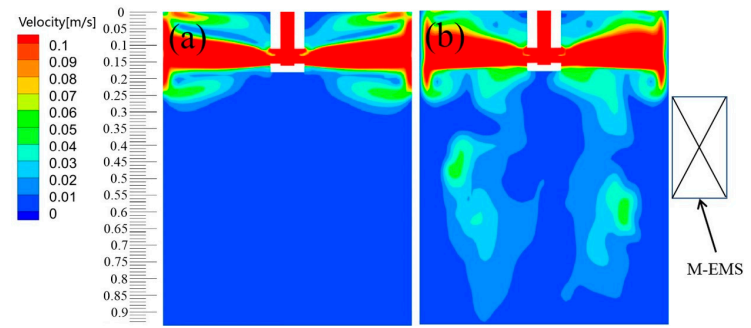

Figure 8. Velocity distribution of the longitudinal section: (a) without M-EMS; (b) with M-EMS.

The temperature distribution of the longitudinal section and four lateral sections, both without and with M-EMS, is shown in Figures 9 and 10. Figures 9a and 10a show that the internal wall of the mold is impinged by the jet pouring from the four-port SEN, resulting in no initial shell generation at the impact location in the absence of M-EMS. The use of M-EMS increased the high temperature near the meniscus, which favored the melting of flux powder, as shown in Figure $9 b$, and reduced the direct impingement of high-temperature molten steel on the initial shell, as shown in Figure 10b. Overall, M-EMS reduces the heat of molten steel and promotes the growth of the initial shell.

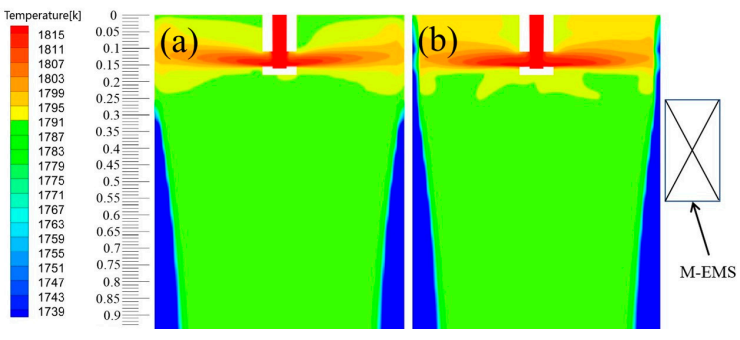

Figure 9. Temperature distribution of the longitudinal section: (a) without M-EMS; (b) with M-EMS.
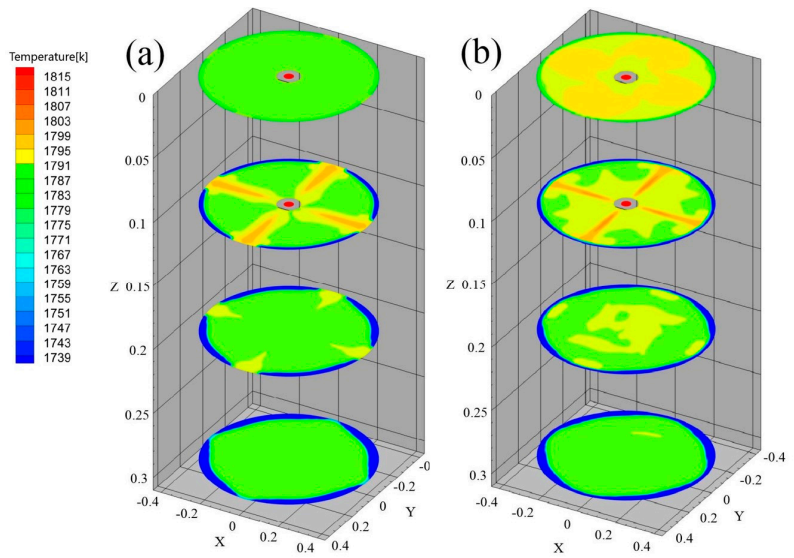

Figure 10. Temperature distribution in the top region of the mold: (a) Without M-EMS; (b) with M-EMS.

The better the initial shell growth is, the fewer surface defects will be in the final products. Table 6 shows the difference in shell thickness at the mold outlet, measured using the initial shell growth discrimination method. As can be observed, the difference value of thickness is reduced by M-EMS so that the initial shell is uniform. Figure 11 shows the 
height fluctuation of the liquid level. With M-EMS, the level fluctuation is smaller than it would be without M-EMS, so it is evident that M-EMS reduces level fluctuation. Slag entrainment from the surface of the mold greatly influences steel quality. Powder entrainment is decreased with the increase in the stability of the surface level.

Table 6. The difference value of shell thickness with M-EMS and without M-EMS.

\begin{tabular}{cc}
\hline Items & Value \\
\hline With M-EMS, mm & 15.61 \\
Without M-EMS, mm & 23.75 \\
\hline
\end{tabular}

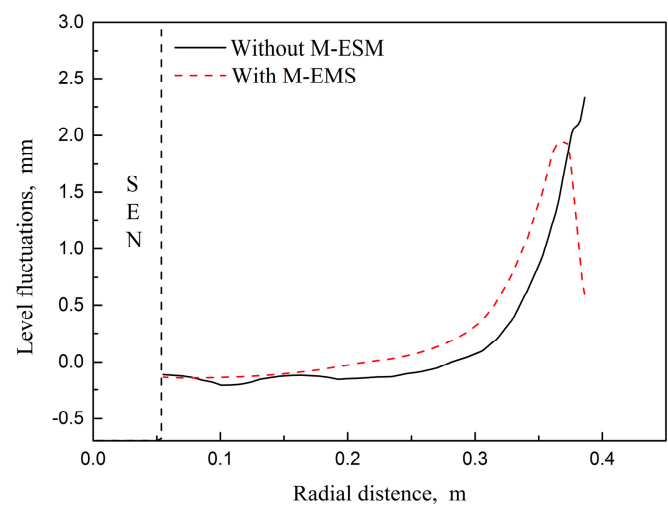

Figure 11. Height fluctuation of the liquid level of without and with M-EMS.

\subsection{Effect of M-EMS Current Frequency on Behavior of Flow and Solidification}

The velocity distribution can be seen in Figure 12a-e for various current frequencies (300 A current intensity, $1 \mathrm{~Hz}$ to $5 \mathrm{~Hz}$ frequency). The velocity of the central molten steel gradually decreases as the frequency increases, from $Z=0.2 \mathrm{~m}$ to $Z=0.4 \mathrm{~m}$, due to the "surface effect". The velocity field is different when the current frequency is $1 \mathrm{~Hz}$, as shown in Figure 12a, because the magnetic flux density is greater than the other current frequencies, regardless of whether the measuring line is axial or radial. Using M-EMS, the velocity field is greatly influenced by the magnetic flux density. In this regard (Figure 12c-e), the position where the maximum velocity is located in the region of $Z=0.3 \mathrm{~m}$ to $Z=0.9 \mathrm{~m}$ is close to the mold outlet due to the magnetic shielding of the copper mold and the position where the maximum magnetic flux density is located, which is close to the mold outlet.
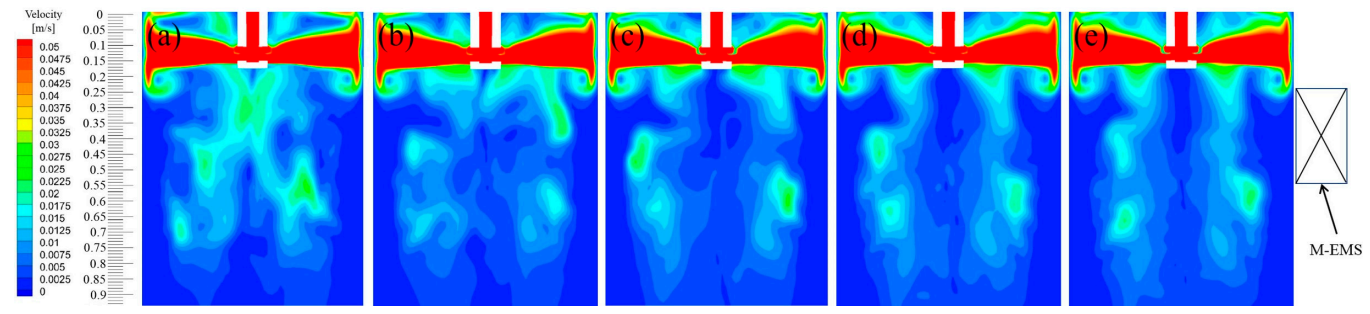

Figure 12. Velocity distribution of the longitudinal section: (a) $1 \mathrm{~Hz}$; (b) $2 \mathrm{~Hz}$; (c) $3 \mathrm{~Hz}$; (d) $4 \mathrm{~Hz}$; (e) $5 \mathrm{~Hz}$.

The temperature distribution is mainly determined by the velocity distribution. Figure 13a-e demonstrates the temperature distribution of the longitudinal section at different current frequencies. Since the velocity essentially distributes in the center of the longitudinal section, as shown in Figure 12a,b, the distance that the heat travels between the center molten steel and the mold is increased. Thus, in Figure 13a,b, the temperatures are higher, in the range of $Z=0.2 \mathrm{~m}$ to $\mathrm{Z}=0.55 \mathrm{~m}$, than in Figure $13 \mathrm{c}-\mathrm{e}$. In this case, the heat transfer is increasing when the center molten steel velocity is low but the frequency is high. However, as shown in Figure 13c-e, the temperature distribution is essentially the same, which means that the increase in frequency has a limited effect on the improvement of heat transfer. 


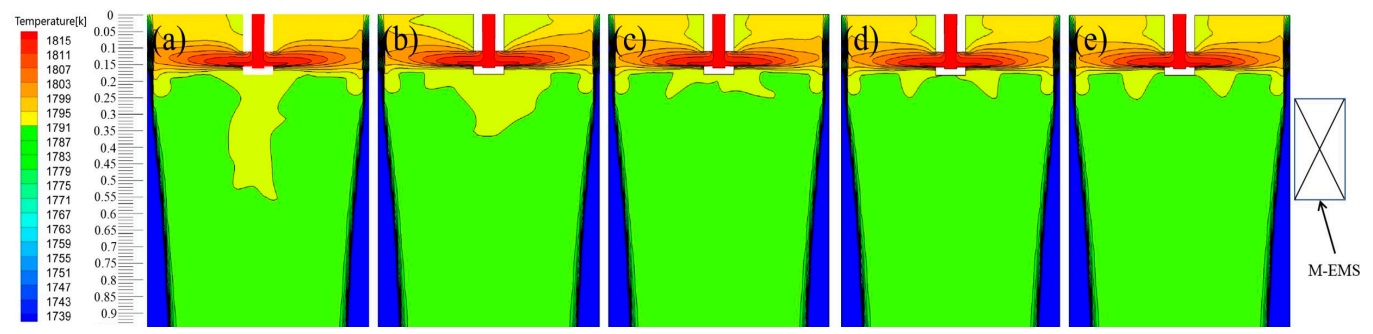

Figure 13. Temperature distribution of the longitudinal section: (a) $1 \mathrm{~Hz}$; (b) $2 \mathrm{~Hz}$; (c) $3 \mathrm{~Hz}$; (d) $4 \mathrm{~Hz}$; (e) $5 \mathrm{~Hz}$.

Since the melting of flux powder depends on the high temperature, it is interesting to examine its distribution in the top region of the mold. Figure 14a-e demonstrates the temperature distribution in the top region of the mold at different current frequencies. As seen in those figures, the temperature of the lateral section at $\mathrm{Z}=0 \mathrm{~m}$ developed away from the center due to the magnetic penetration being decreased by the increase in frequency. The electromagnetism could not affect the molten steel. When the current frequency is $1 \mathrm{~Hz}$ to $4 \mathrm{~Hz}$ (Figure 14a-d), the temperature of the lateral section at $\mathrm{Z}=0.2 \mathrm{~m}$ develops outward due to the "surface effect"; the higher the frequency is, the greater the magnetic flux density concentrate in the billet surface. Moreover, the velocity distribution is greatly determined by the magnetic flux density distribution in the mold, which further changes the temperature distribution. When the frequency is $4 \mathrm{~Hz}$ and $5 \mathrm{~Hz}$ (Figure 14d,e), the temperature distribution of the lateral section is essentially the same because of the fixed current intensity; the molten steel jet from the nozzle and the rotating molten steel affected by a magnetic field are the main flows in the top region of the mold.
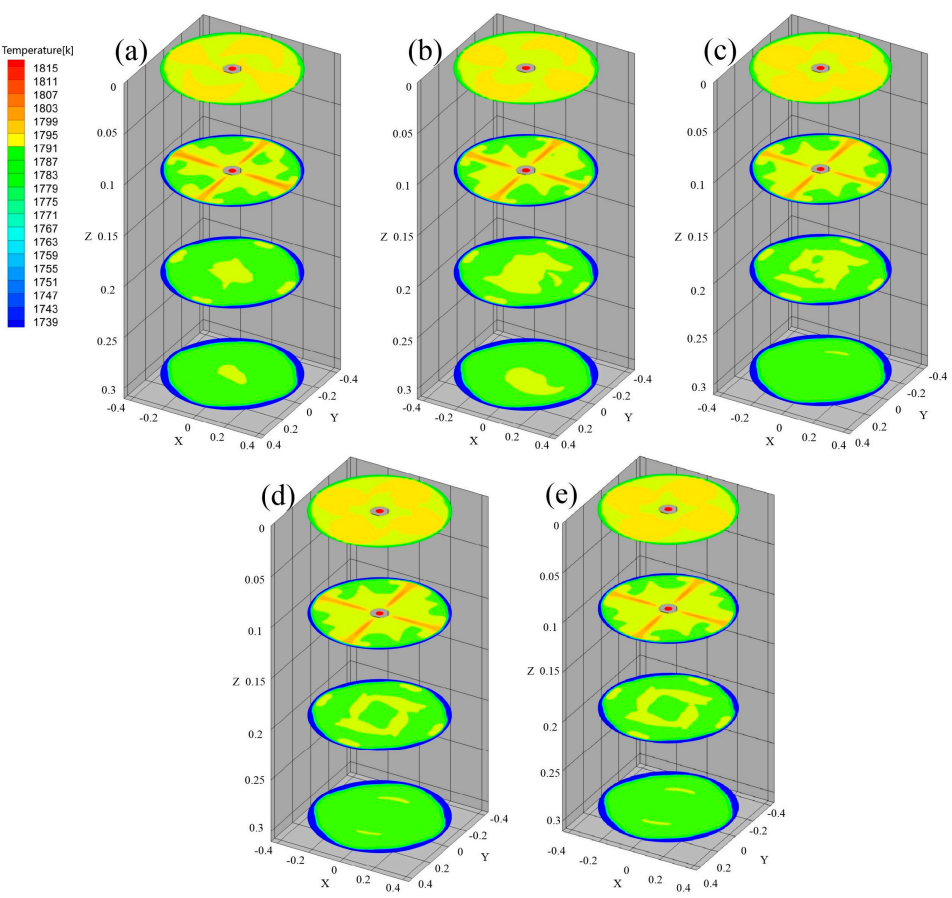

Figure 14. Temperature distribution in the top region of the mold: (a) $1 \mathrm{~Hz}$; (b) $2 \mathrm{~Hz}$; (c) $3 \mathrm{~Hz}$; (d) $4 \mathrm{~Hz}$; (e) $5 \mathrm{~Hz}$.

Table 7 shows the difference value of the shell thickness at the mold outlet, measured by the initial shell growth discrimination method. When the frequency is $3 \mathrm{~Hz}$ to $5 \mathrm{~Hz}$, the difference value is essentially the same because there is a subtle difference in the velocity and temperature distributions, and the initial shell is mainly determined by the velocity and temperature distributions. When the frequency is $3 \mathrm{~Hz}$, the difference value is the 
lowest, indicating that the initial shell growth is optimal. Figure 15 demonstrates the height fluctuation of the liquid level. As seen in this figure, the height fluctuation is at a minimum when the frequency is $3 \mathrm{~Hz}$. The more stable the surface level, the lower the powder entrainment. Closer inspection of this figure shows that the maximum fluctuation is concentrated at the edge of the mold due to the molten steel, which is driven by magnetic force, generating centrifugation of the fluid flow.

Table 7. The difference values of shell thickness of the different current frequencies.

\begin{tabular}{cc}
\hline Items & Value \\
\hline $1 \mathrm{~Hz}, \mathrm{~mm}$ & 16.21 \\
$2 \mathrm{~Hz}, \mathrm{~mm}$ & 15.85 \\
$3 \mathrm{~Hz}, \mathrm{~mm}$ & 15.61 \\
$4 \mathrm{~Hz}, \mathrm{~mm}$ & 15.71 \\
$5 \mathrm{~Hz}, \mathrm{~mm}$ & 15.74 \\
\hline
\end{tabular}

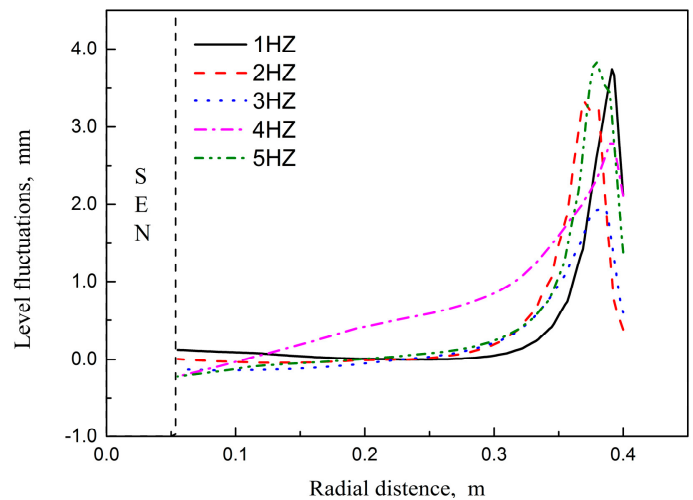

Figure 15. Height fluctuation of the liquid level of different current frequencies.

\subsection{Effect of M-EMS Current Intensity on Behavior of Flow and Solidification}

Figure 16 demonstrates the velocity distribution of the longitudinal section at different current intensities. The current frequency is $3 \mathrm{~Hz}$, and the current intensities are $200 \mathrm{~A}$, 300 A, 350 A, 375 A, 400 A, 450 A, 500 A, and 600 A. As seen in Figures 12 and 16, the stirring velocity is mainly affected by the current intensity compared to the current frequency. The fluid flow in the range of $0.3 \mathrm{~m}$ to $0.9 \mathrm{~m}$ is non-uniform due to the magnetic force, which drives the molten steel, effects on both sides of the mold being different. Because of the fixed current frequency and the magnetic shielding, the magnetic flux density is concentrated in the mold outlet position; meanwhile, the velocity distribution is greatly determined by the magnetic flux density distribution in the region of the mold, so the maximum velocity is near the mold outlet.

Figure 17 demonstrates the temperature distribution of the longitudinal section at different current intensities. As seen in those figures, temperatures in the range of $0 \mathrm{~m}$ to $0.2 \mathrm{~m}$ decay rapidly due to the increase in current intensity increasing the molten steel rotating velocity; meanwhile, the temperature distribution is mainly determined by the velocity distribution, and thus the heat transfer is increased by the rotating molten steel. It should be noted that the initial shell is not generated in the range of $0.15 \mathrm{~m}$ to $0.25 \mathrm{~m}$, when the current intensity is 200 A (Figure 17a) due to the lower current intensity, the molten steel jet from the nozzle is the main flow, indicating that the lower current intensity may not achieve ideal results. In short, the stirring current intensity should not be too low. 

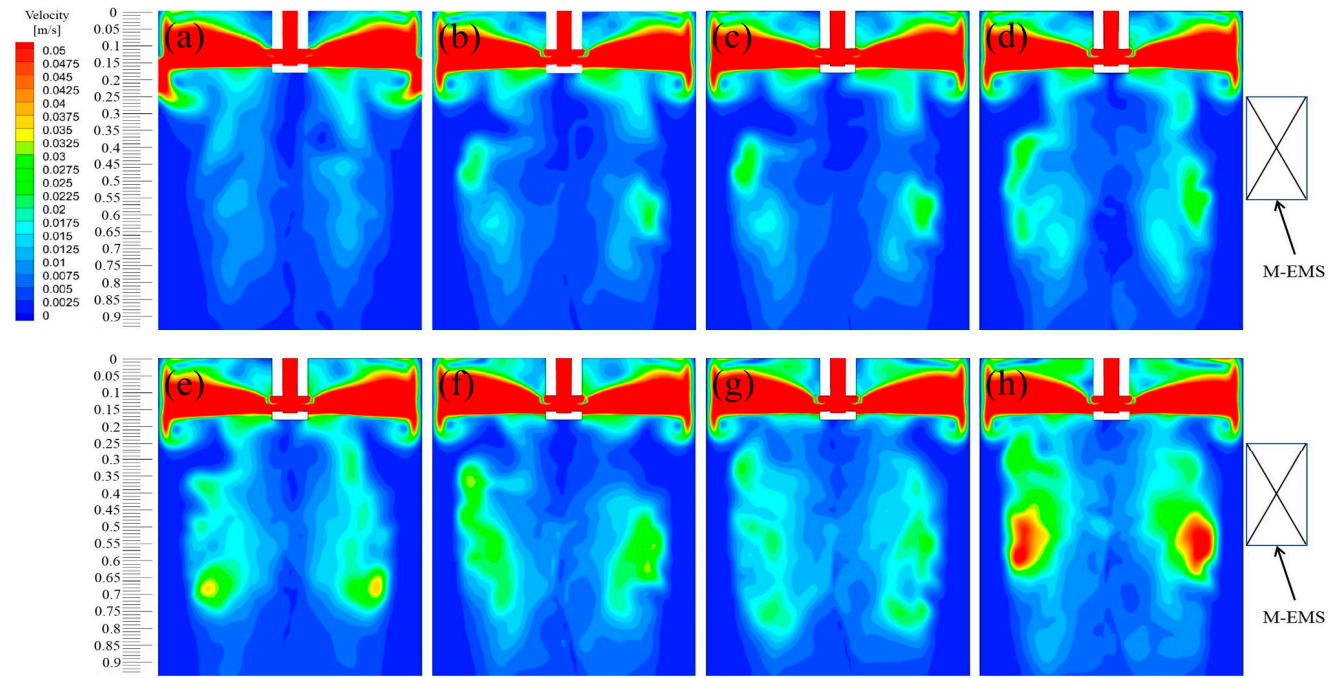

Figure 16. Velocity distribution of the longitudinal section: (a) $200 \mathrm{~A}$; (b) $300 \mathrm{~A}$; (c) $350 \mathrm{~A}$; (d) $375 \mathrm{~A}$; (e) $400 \mathrm{~A}$; (f) $450 \mathrm{~A}$; (g) $500 \mathrm{~A}$; (h) $600 \mathrm{~A}$.
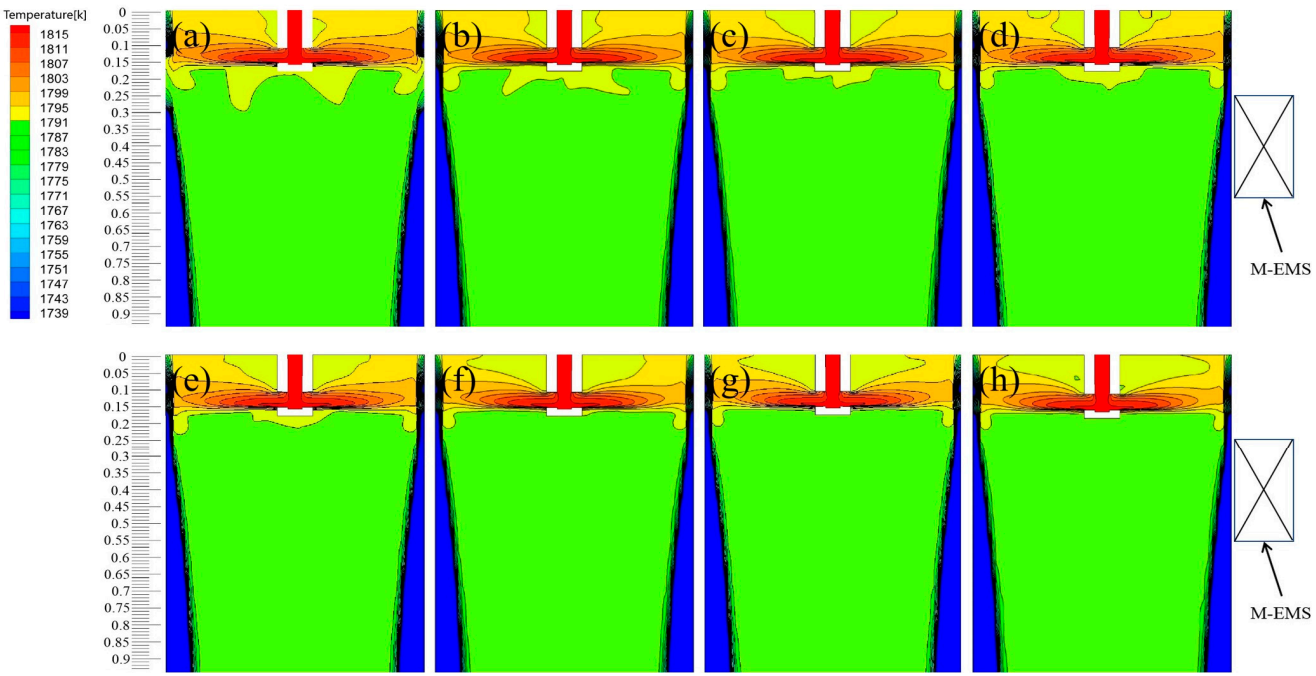

Figure 17. Temperature distribution of the longitudinal section: (a) $200 \mathrm{~A}$; (b) $300 \mathrm{~A}$; (c) $350 \mathrm{~A}$; (d) $375 \mathrm{~A}$; (e) $400 \mathrm{~A}$; (f) $450 \mathrm{~A}$; (g) $500 \mathrm{~A}$; (h) $600 \mathrm{~A}$.

Figure 18 demonstrates the temperature distribution in the top region of the mold at different current intensities. As shown in those figures, the temperatures are gradually decreasing at the $\mathrm{Z}=0 \mathrm{~m}$ lateral section. The rotating steel velocity is greatly determined by the magnetic flux density, and the temperature distribution is mainly determined by the velocity distribution so that the heat transfer increases with the increase in current intensity. Moreover, because the lower the temperature in the top region of the mold, the slower the melting rate of flux powder, this can be an issue for producing high-quality products. However, these effects are complex, including both the dissipation of heat and the stirring velocity. 

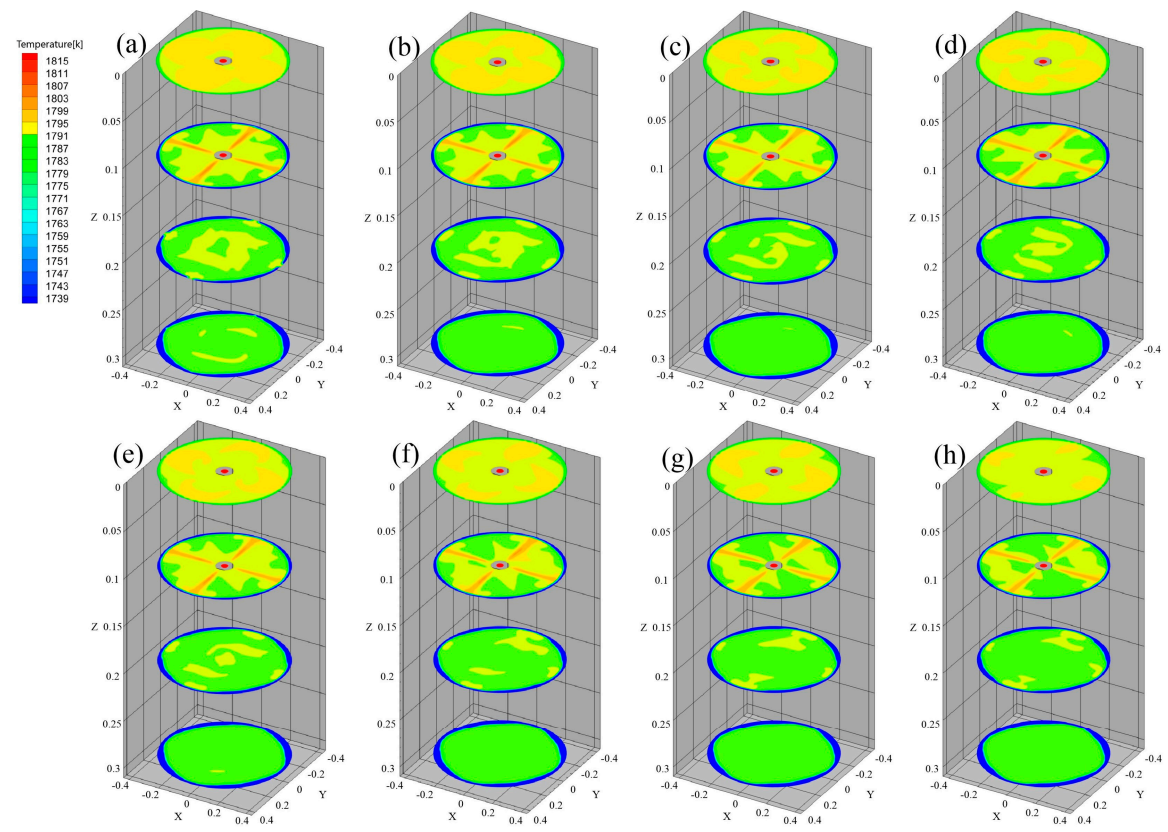

Figure 18. Temperature distribution in the top region of the mold: (a) $200 \mathrm{~A}$; (b) $300 \mathrm{~A}$; (c) $350 \mathrm{~A}$; (d) $375 \mathrm{~A}$; (e) $400 \mathrm{~A}$; (f) $450 \mathrm{~A}$; (g) $500 \mathrm{~A}$; (h) $600 \mathrm{~A}$.

Table 8 demonstrates the difference value of shell thickness at the mold outlet. The difference value of shell thickness at the mold outlet is non-ideal if the current intensity is too large or too small. It should be noted that the increase in current intensity may not make the initial shell uniform; thus, it is instructive for choosing the appropriate stirring current intensity. Because the increase in current intensity not only increases the dissipation of heat but also increases the velocity of molten steel, the impingement of molten steel on the initial shell is also enhanced. The difference value is the lowest when the current intensity is $375 \mathrm{~A}$ so that the initial shell growth is the best. Figure 19 demonstrates the height fluctuation of the liquid level. The fluctuation forms are different, and the highest value is found at the edge of the mold. As seen in Figures 15 and 19, for the given current frequency and current intensity, the level fluctuation is mainly affected by the current intensity compared to the current frequency. Closer inspection of this figure shows that the height of the fluctuation of the liquid level is $1.01 \mathrm{~mm}$ and $1.29 \mathrm{~mm}$ when the current intensity is $350 \mathrm{~A}$ and $375 \mathrm{~A}$, respectively, which meets the actual production requirements.

Table 8. The difference values of shell thickness of the different current intensities.

\begin{tabular}{cccc}
\hline Items & Value & Items & Value \\
\hline $200 \mathrm{~A}, \mathrm{~mm}$ & 16.51 & $400 \mathrm{~A}, \mathrm{~mm}$ & 15.79 \\
$300 \mathrm{~A}, \mathrm{~mm}$ & 15.61 & $450 \mathrm{~A}, \mathrm{~mm}$ & 17.81 \\
$350 \mathrm{~A}, \mathrm{~mm}$ & 15.82 & $500 \mathrm{~A}, \mathrm{~mm}$ & 17.73 \\
$375 \mathrm{~A}, \mathrm{~mm}$ & 15.48 & $600 \mathrm{~A}, \mathrm{~mm}$ & 17.44 \\
\hline
\end{tabular}

Besides, strong or weak swirling flow may not make the initial shell uniform or stabilize the level fluctuation at the same current frequency and different current intensities. Thus, in brief, the selection of current intensity is the most important. 


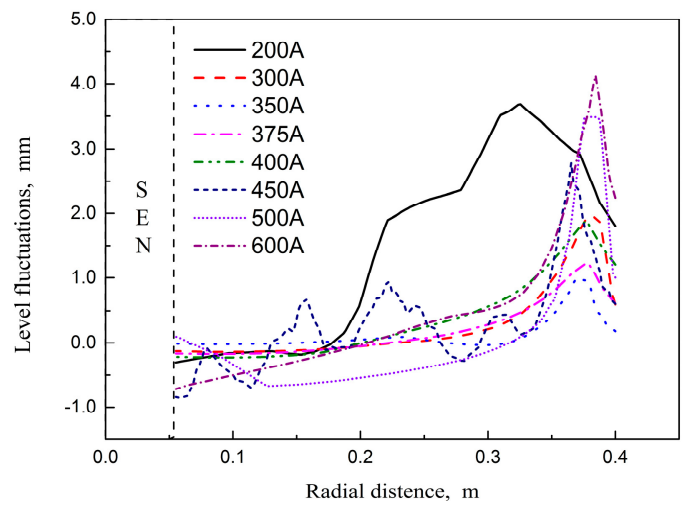

Figure 19. Height fluctuation of the liquid level of different current intensities.

\subsection{Optimization}

According to the results of the mathematical simulation, the optimal stirring intensity was determined to be $375 \mathrm{~A} / 3 \mathrm{~Hz}$. Fundamentally based machines measuring level fluctuation are now sufficiently accurate and efficient to the point that they are being used as a part of online control systems. Thus, the industrial test of the height fluctuation of the liquid level was carried out by online control systems to prove the optimization effect.

Figure 20 demonstrates the height fluctuation when optimized and not optimized. It is observed that the largest height fluctuation was less than $2 \mathrm{~mm}$ whether optimized is or not. Moreover, the maximum industrial height fluctuation was reduced from $1.9 \mathrm{~mm}$ to $1.3 \mathrm{~mm}$, and thus the practicality of the electromagnetic parameters was confirmed.

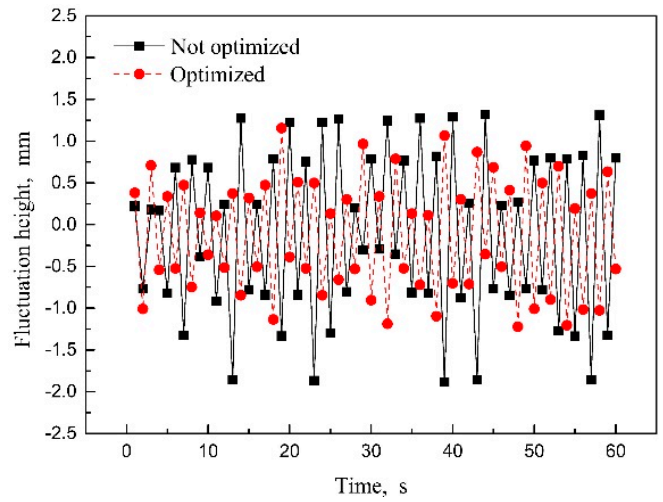

Figure 20. Fluctuation height of liquid level.

\section{Conclusions}

1. The magnetic flux density is mainly determined by the current frequency and current intensity. On the axial measuring line, the distribution of magnetic flux density is large in the center and small on the edge, and the maximum magnetic flux density is basically concentrated in the mold outlet. On the radial measuring line, the magnetic flux density is small in the center and large on the edge.

2. M-EMS can improve the temperature distribution near the meniscus and reduce the direct impingement of high-temperature molten steel on the initial shell, make the initial shell uniform, and reduce the height fluctuation.

3. The current frequency has a limited effect on the temperature and velocity; higher current frequency and current intensity cannot make the initial shell uniform or stabilize the level fluctuation. The initial shell growth and level fluctuation are greatly determined by the current intensity compared to the current frequency.

4. The difference value of shell thickness was the smallest and the height fluctuation of liquid level was controlled within $2 \mathrm{~mm}$ when the stirring intensity was $375 \mathrm{~A} / 3 \mathrm{~Hz}$; thus, the stirring intensity of the industrial test was determined to be $375 \mathrm{~A} / 3 \mathrm{~Hz}$. 
Meanwhile, when the maximum industrial height fluctuation was reduced from $1.9 \mathrm{~mm}$ to $1.3 \mathrm{~mm}$, the stirring intensity was relatively ideal.

Author Contributions: Conceptualization, C.X.; methodology, C.X. and L.Z.; software, T.W. and P.Y.; validation, T.W. and H.W.; formal analysis, T.W. and X.Z.; investigation, C.X. and L.Z.; resources, C.X.; writing - original draft preparation, T.W.; writing-review and editing, C.X. and T.W.; supervision, Y.J. and L.Z.; All authors have read and agreed to the published version of the manuscript.

Funding: This research received no external funding.

Institutional Review Board Statement: Not applicable.

Informed Consent Statement: Not applicable.

Data Availability Statement: The data presented in this study are available on request from the corresponding author. The data are not publicly available due to privacy restrictions.

Acknowledgments: The authors are grateful for the support from the Henan Zhongyuan Special Steel Equipment Manufacturing Co.

Conflicts of Interest: The authors declare no conflict of interest.

\section{References}

1. Zhang, L.W.; Wang, Z.L.; Xu, C.J.; Li, S.L.; Ai, X.G.; Li, J. A vertical continuous casting machine for large blooms. Ironmak. Steelmak. 2019, 46, 742-746. [CrossRef]

2. Michelic, S.; Riedler, M. Production of Jumbo Blooms by Semi-continuous Casting: Challenges, Feasibility, and Future Potential. BHM Berg-und Hüttenmännische Mon. 2016, 161, 39-44. [CrossRef]

3. Yu, H.Q.; Zhu, M.Y. Influence of electromagnetic stirring on transport phenomena in round billet continuous casting mold and macrostructure of high carbon steel billet. Ironmak. Steelmak. 2012, 39, 574-584. [CrossRef]

4. Liu, H.P.; Xu, M.G.; Qiu, S.T.; Zhang, H. Numerical Simulation of Fluid Flow in a Round Bloom Mold with In-Mold Rotary Electromagnetic Stirring. Metall. Mater. Trans. B 2012, 43, 1657-1675. [CrossRef]

5. Javurek, M.; Barna, M.; Giltter, P.; Rockenschaub, K.; Lechner, M. Flow Modelling in Continuous Casting of Round Bloom Strands with Electromagnetic Stirring. Steel Res. Int. 2008, 79, 617-626. [CrossRef]

6. Song, X.P.; Cheng, S.S.; Cheng, Z.J. Mathematical modelling of billet casting with secondary cooling zone electromagnetic stirrer. Ironmak. Steelmak. 2012, 40, 189-198. [CrossRef]

7. Trindade, L.B.; Nadalon, J.E.A.; Contini, A.C.; Barroso, R.C. Modeling of Solidification in Continuous Casting Round Billet with Mold Electromagnetic Stirring (M-EMS). Steel Res. Int. 2017, 88, 1600319. [CrossRef]

8. Maurya, A.; Jha, P.K. Influence of electromagnetic stirrer position on fluid flow and solidification in continuous casting mold. Appl. Math. Model. 2017, 48, 736-748. [CrossRef]

9. Sun, H.; Zhang, J. Effect of Feeding Modes of Molten Steel on the Mold Metallurgical Behavior for Round Bloom Casting. ISIJ Int. 2011, 51, 1657-1663. [CrossRef]

10. Wang, Y.; Zhang, L.; Yang, W.; Ji, S.; Ren, Y. Effect of Mold Electromagnetic Stirring and Final Electromagnetic Stirring on the Solidification Structure and Macrosegregation in Bloom Continuous Casting. Steel Res. Int. 2021, 92, 2000661. [CrossRef]

11. Maurya, A.; Kumar, R.; Jha, P.K. Simulation of electromagnetic field and its effect during electromagnetic stirring in continuous casting mold. J. Manuf. Processes 2020, 60, 596-607. [CrossRef]

12. Li, Y.G.; Sun, Y.H.; Bai, X.S. Numerical Simulation of Flow, Heat, Solidification, Solute Transfer and Electromagnetic Field for Vertical Mold and Curved Mold of Billet. ISIJ Int. 2021, 61, 802-813. [CrossRef]

13. Huo, Y.K.; Zhao, L.H.; An, H.H.; Wang, M.; Zou, C.D. Model prediction of the effect of in-mould electromagnetic stirring on negative segregation under bloom surface. Int. J. Miner. Metall. Mater. 2020, 27, 317-327. [CrossRef]

14. Guan, R.; Li, C.; Zhu, M.Y. Modeling the Effect of Combined Electromagnetic Stirring Modes on Macrosegregation in Continuous Casting Blooms. Metall. Mater. Trans. B 2020, 51, 1137-1153. [CrossRef]

15. Fang, Q.; Zhang, H.; Wang, J.; Liu, C.; Ni, H. Effect of Electromagnetic Stirrer Position on Mold Metallurgical Behavior in a Continuously Cast Bloom. Metall. Mater. Trans. B 2020, 51, 1705-1717. [CrossRef]

16. Liu, H.; Wang, Z.; Qiu, H. Numerical Simulation of Fluid Flow and Solidification in a Vertical Round Bloom Caster Using a Four-port SEN with Mold and Strand Electromagnetic Stirring. ISIJ Int. 2020, 60, 1924-1937. [CrossRef]

17. Zhang, L.W.; Xu, C.J.; Wang, C.; Wang, C.; Wang, T.; Zhang, X.B.; Wu, H.J. The simulation of mold metallurgical behaviour under electromagnetic stirring for vertical large bloom. Ironmak. Steelmak. 2021, 48, 1220-1225. [CrossRef]

18. Zhang, L.; Xu, C.; Zhang, J.; Wang, T.; Li, J.; Li, S. The Simulation and Optimization of an Electromagnetic Field in a Vertical Continuous Casting Mould for a Large Bloom. Metals 2020, 10, 516. [CrossRef]

19. Aboutalebi, M.R.; Hasan, M.; Guthrie, R.I.L. Coupled turbulent flow, heat, and solute transport in continuous casting processes. Metall. Mater. Trans. B 1995, 26, 731-744. [CrossRef] 